\title{
Simultaneous and fast determination of antibiotics as nitrofuran metabolites in fish and shrimp muscle using Enzyme-Linked Immunosorbent Assay (ELISA)
}

\author{
MD. MEZANUR RAHMAN*, MD. MAHMUDUL HASAN RONY, \\ K.M. GOLZAR HOSSAIN, MD. GOLAM MOSTOFA, SALMA BEGUM \\ AND SHAMSHAD B. QURAISHI ${ }^{1}$ \\ Quality Control Laboratory, Chattogram, Department of Fisheries, Bangladesh \\ ${ }^{1}$ Analytical Chemistry Laboratory, Chemistry Division, Atomic Energy Centre, Dhaka, Bangladesh \\ *Email: mezanur.ict94@gmail.com
}

\begin{abstract}
A simultaneous and fast analytical method was developed for the identification of four nitrofuran metabolites from the fish and shrimp samples. Homogenized samples were hydrolyzed and derivatized with 4-nitrobenzaldehyde. Subsequently, extracted with ethyl acetate, evaporated to dryness and the residue was re-dissolved in Hexane. Commercial enzyme-linked immunosorbent assay (ELISA) method was applied for the analysis of nitrofuran metabolites. The method was validated in shrimp and fish matrix according to the criteria defined in Commission Decision 2002/657/EC for qualitative screening method following the guidelines set by the community reference laboratories residues (CRLs) 2010. Characteristic's parameters as detection capability $(\mathrm{CC} \beta)$, specificity/selectivity, stability, recovery and precision were determined. Detection capability (CC $\beta$ ) for nitrofuran metabolites (AMOZ, AOZ, AHD and SEM) in Fish and shrimp matrix was in the range of $0.5-0.75 \mu \mathrm{g} / \mathrm{kg}$, which were less than the Minimum Required Performance Limit (MRPL) of $1 \mu \mathrm{g} / \mathrm{kg}$ set by European Union. The proposed method is suitable for semi-quantitative screening analysis of antibiotics in the fish and shrimp muscle in conformity with the current EU performance requirements before exporting to EU and other countries. Results from analysis of unknown samples by the developed ELISA method were comparable to those obtained by a liquid chromatography-tandem mass spectrometry (LCMS/MS) method. Accuracy and precision of the method had also been checked through participation of International Proficiency Testing (PT) having a very satisfactory performance score.

Keywords: Nitrofuran metabolites, Fish and Shrimp, СC $\beta$.
\end{abstract}

\section{Introduction}

Fish and fish products are the major export commodities of Bangladesh. Bangladeshi fish and fish products are exported to many countries of the world. Bangladesh exports around $70 \%$ of its exportable fish and fish products to EU countries (DoF 2019). Contamination of fish and fish products by different harmful chemical substances as major food safety concern to the customers (DoF 2014). In recent years, with the rise of aquaculture as one of the fastest-growing industries in developing countries, the use of prohibited antimicrobial drugs such as nitrofurans has raised public health concerns. Nitrofurans are a class of antibacterial drugs, had been widely and effectively used for the prevention and treatment of bacterial diseases of animals as well as to enhance feed efficiency, promote animal growth and improve productivity. Use of nitrofurans in aquaculture was banned by many countries including European Union (Commission 
Regulation 1995) and Bangladesh because of their potentially carcinogenic and mutagenic effects on human health (Hossain et al. 2013). As a result of their rapid metabolism, nitrofuran parent substances are not suitable for monitoring and typically their metabolites are analyzed (Alam et al. 2014). In order to strictly monitor the use of nitrofurans in aquatic products, the fast, simple, sensitive and cost-effective technologies and methods for analysis of nitrofuran residues is essential. In the past decades, several analytical methods had been developed for the screening and quantitation of nitrofurans in foods and biological samples (Alam et al. 2014). Confirmatory methods are highly effective, but also long, tedious, expensive and they require highly trained personnel. Screening methods are a cheaper alternative. The high sensitivity, specificity and accuracy, with the added advantage of being inexpensive and the possibility of analyzing a large number of samples within a short period of time has made ELISA tests one of the most popular choices for screening drug residues in food.

In this study, a simultaneous and rapid analytical method was developed for the determination of four nitrofuran metabolites (AOZ, AMOZ, AHD and SEM) in fish and shrimp samples. Commercial enzyme-linked immunosorbent assay (ELISA) technique has been applied for the analysis of nitrofuran metabolites. The method was validated in shrimp and fish matrix according to the criteria defined in Commission Decision 2002/657/EC for qualitative screening method following the guidelines set by the community reference laboratories residues (CRLs) 2010.

\section{Materials and Methods}

Apparatus and glassware: A Micro plate reader equipped with a $450 \mathrm{~nm}$ filter (ELx $800^{\mathrm{TM}}$, BioTek, USA), Waterbath (281 ANALOG, Cole Parmer), 4 decimal points analytical balance (AND,Germany ), Centrifuge (5810, Eppendorf, Germany), Vortex (Barnsteed, Germany), Micropipettes (Eppendorf, Germany), Nitrogen evaporator (Organomation Associates Int.), Polypropylene centrifuge tubes (Griner, B 532), GlassTest tube (Pyrex) and Volumetric flasks (Schoot Duran) were used to prepare samples and perform extraction.

Reagents, chemicals and standards: All chemicals and solvents used were of analytical reagent grade except Ethyl acetate that was HPLC grade. Deionized water was obtained from barnstead smart2 pure system (Thermo Scientific, Germany). Ethyl acetate, n-Hexane, $\mathrm{HCl}, \mathrm{NaOH}$, $\mathrm{K}_{2} \mathrm{HPO}_{4}$, and $N, N$-dimethylformamide were obtained from Sigma Aldrich, Germany. The nitrofuran metabolites ELISA kits (NF3461-3463, NF3465) produced by Randox Laboratories Ltd, UK were used. Nitrofuran Metabolites (AOZ, AMOZ, AHD, SEM) Standards were obtained from Sigma Aldrich, Germany. Stock standard solutions of the four compounds $(100 \mathrm{ng} / \mathrm{ml})$ were prepared by dissolving each one in $N, N$-dimethylformamide and store at $-20^{\circ} \mathrm{C}$. Working mixed standard solutions $(10 \mathrm{ng} / \mathrm{ml})$ of the compounds were freshly prepared from the stock standard solutions.

Sample preparation: After brought to the laboratory, known blank fish and shrimp samples were washed with tap water. Head, shell of shrimps and scales of fish were removed from the body. Flesh was taken out from the bone of fish. Around $200 \mathrm{~g}$ homogenised paste was prepared from the samples using blender and stored at $-20^{\circ} \mathrm{C}$. 
Extraction procedure: $1 \mathrm{~g}$ of homogenised muscle was taken into a $50 \mathrm{ml}$ polypropylene tube and $4 \mathrm{ml}$ double distilled $\mathrm{H}_{2} \mathrm{O}, 0.5 \mathrm{ml} 1 \mathrm{M} \mathrm{HCl}, 75 \mu \mathrm{l} 10 \mathrm{mM}$ 4-Nitrobenzaldehyde (in DMSO) were added and vortexed for $1 \mathrm{~min}$. The mixture was incubated for $2 \mathrm{hrs}$ at $50^{\circ} \mathrm{C}$ in a water bath and then kept at room temperature for $10 \mathrm{~min} .5 \mathrm{ml} 0.1 \mathrm{M} \mathrm{K}_{2} \mathrm{HPO}_{4}, 0.4 \mathrm{ml} 1 \mathrm{M} \mathrm{NaOH}$ and $6 \mathrm{ml}$ ethyl acetate were added to the sample and vortexed for $1 \mathrm{~min}$. After centrifugation (10 min at $4000 \mathrm{rpm}$ at $25^{\circ} \mathrm{C}$ ) $3 \mathrm{ml}$ of the upper ethyl acetate layer was evaporated at $60^{\circ} \mathrm{C}$ under $\mathrm{N} 2$ stream and re-dissolved in $1 \mathrm{ml}$ hexane and $1 \mathrm{ml}$ dilution buffer provided with the ELISA kit. After 10 min centrifugation at $4000 \mathrm{rpm}$ at $25^{\circ} \mathrm{C}, 50 \mu 1$ of lower phase was used for the analysis.

Validation study: According to 2002/675/EC for validation of qualitative screening method, determination of detection capability $\mathrm{CC} \beta$ (the smallest content of the analyte that may be detected, identified and/or quantified in a sample with an error probability of $\beta$ ), specificity/selectivity and applicability/ruggedness/stability are mandatory. Validation of screening methods (whether qualitative or semi-quantitative) also requires identification of a Cut-Off Level at, or above which the sample is categorised as 'screen positive' and liable to physicochemical confirmation (CRL 2010).

Detection capability $C C \beta$ and cutoff level: The CC $\beta$ and cut-off level were established by analysing 20 blank samples and 20 spiked samples for each investigated matrix. Matrix blank samples were spiked with nitrofuran metabolites at the screening target concentration. In case of SEM, 40 blank and 40 spiked samples for each investigated matrix were tested. Minimum Required Performance Limit (MRPL) for each of the nitrofuran metabolites is $1 \mu \mathrm{g} / \mathrm{kg}$ set by European Union (EC Decision 181, 2003), so screening target concentration was set at $0.5 \mu \mathrm{g} / \mathrm{kg}$ for AOZ, AMOZ and AHD and $0.75 \mu \mathrm{g} / \mathrm{kg}$ for SEM. Blank and spiked samples were analyzed at three different days with three analysts. Each data set contained duplicate measurements reading. The range of analytical responses for the blank samples and the range for the spiked samples were evaluated. As the lowest response for the spiked samples was not overlap with the highest response for the blank sample, the lowest response in the spiked samples was selected as the Cut-Off Level and detection capability $\mathrm{CC} \beta$ was less than or equal to the screening target concentration.

The $\beta$ error was calculated using a statistical approach which takes into account the $\beta$ error of 5\%. According to the Commission Decision 2002/657/EC, the detection capability is validated when: $\mathrm{Fm}>\mathrm{B}$. Also the rate of false positive (FP) is determined which is acceptable with the method. If $\mathrm{B}<\mathrm{Fm}<\mathrm{T}$, the false positive rate is higher than $5 \%$. In case of $\mathrm{Fm}>\mathrm{T}$, the rate of false positive is below $5 \%$ where, $\mathrm{B}$ is the mean responses of Blank, $\mathrm{T}$ is the Threshold value, Fm is the Cut-off factor.

Selectivity/specificity and stability. The selectivity/specificity was tested by analysing 20 representative blank samples for each matrix under examination. The stability of analyte in matrix extracted was tested by analysing spiked sample at screening target concentration. Matrix Extracted solution was divided into 3 aliquots. one aliquot was analysed immediately. The remaining aliquots were stored at $-20^{\circ} \mathrm{C}$ and analysed them in two other occasion.

The calculation of the concentration of the analyte in each aliquot carried out by using the formula: Solution of the analyte freshly prepared at the time of analysis as $100 \%$. 


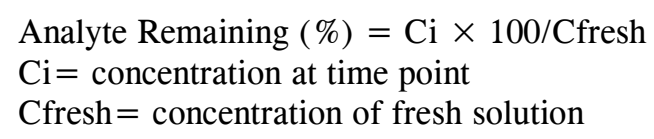

\section{Results and Discussion}

The procedure was simple, fast and effective for simultaneous determination of nitrofuran metabolites. The method validation parameters were complied with EU requirement as shown in Table I. The most critical parameter to be estimated for a screening method is the CC $\beta$ : in the present study, among three possible approaches suggested by European Decision for banned substances (Scortichini et al. 2005), we adopted the method of analyzing 20 blank samples for each investigated matrix spiked with Nitrofuram metabolites (AOZ, AMOZ and AHD) at half of the MRPL concentration and analyzing 40 blank samples spiked with SEM at $75 \%$ of MRPL concentration. This strategy, explicitly referred to qualitative methods, does not permit to establish the exact value of CC $\beta$ (Scortichini et al. 2005), but allows to verify that the $\beta$ error limit is respected at $50 \%$ to $75 \%$ of MRPL concentration. The other approach reported in 2002/657/EC of "analysing at least 20 blank samples per matrix fortified with the analyte(s) at decision limit" is not convenient for a screening method since it is necessary as a preliminary determination of the decision limit $(\mathrm{CC} \alpha)$ with a greater number of experiments to be carried out for each matrix. On the other hand, the alternative approach of matrix calibration curves, according to ISO 11843, is valid only for a linear curve and thus not applicable to ELISA assays. Each of the nitrofuran metabolites was detected in all spiked samples and the lowest response of spiked samples was not overlap the highest response of blank samples (Fig. 1), which means that in fish and shrimp matrix Detection capability $(\mathrm{CC} \beta)$ is less than or equal to $0.5 \mu \mathrm{g} / \mathrm{kg}$ for $\mathrm{AOZ}$, AMOZ and AHD, and is less than or equal to $0.75 \mu \mathrm{g} / \mathrm{kg}$ for SEM, which are less than the Minimum Required Performance Limit (MRPL) of $1 \mu \mathrm{g} / \mathrm{kg}$ set by European Union. Thus the method showing the ability to detect contaminated samples at below the MRPL level with a $\beta$ error lower than $0.05(5 \%)$.

Table I. Validation parameter of nitrofuran metabolites in fish and shrimp

\begin{tabular}{l|c|c|c|c|c|c|c|c}
\hline Compound & $\begin{array}{c}\text { Detection capability } \\
\text { CC } \beta(\mu \mathrm{g} / \mathrm{kg})\end{array}$ & \multicolumn{2}{c|}{$\begin{array}{c}\text { Cutoff level } \\
(\mu \mathrm{g} / \mathrm{kg})\end{array}$} & \multicolumn{2}{c|}{$\begin{array}{c}\text { Recovery at } \\
\mathrm{CC} \beta(\%)\end{array}$} & \multicolumn{2}{c}{$\begin{array}{c}\text { Repeatability at } \\
\mathrm{CC} \beta(\mathrm{CV} \%)\end{array}$} \\
\hline & Fish & Shrimp & Fish & Shrimp & Fish & Shrimp & Fish & Shrimp \\
\hline AOZ & 0.5 & 0.5 & 0.278 & 0.271 & 78 & 76 & 39 & 17 \\
\hline AMOZ & 0.5 & 0.5 & 0.231 & 0.191 & 51 & 56 & 13 & 27 \\
\hline AHD & 0.5 & 0.5 & 0.248 & 0.241 & 76 & 63 & 32 & 14 \\
\hline SEM & 0.75 & 0.75 & 0.601 & 0.750 & 108 & 118 & 27 & 31 \\
\hline
\end{tabular}

As regards the specificity/selectivity, no relevant matrix interference effects were detected during the performed tests. Moreover, no interferences were observed when four metabolites were spiked to the matrix at CC $\beta$ level. The analytes were stable in matrix extract solution with time (up to 4 days) if stored at $-20^{\circ} \mathrm{C}$. The precision and recovery data obtained from the analyses of blank spiked samples at CC $\beta$ levels are reported in Table I. 
MD. MEZANUR RAHMAN et al.
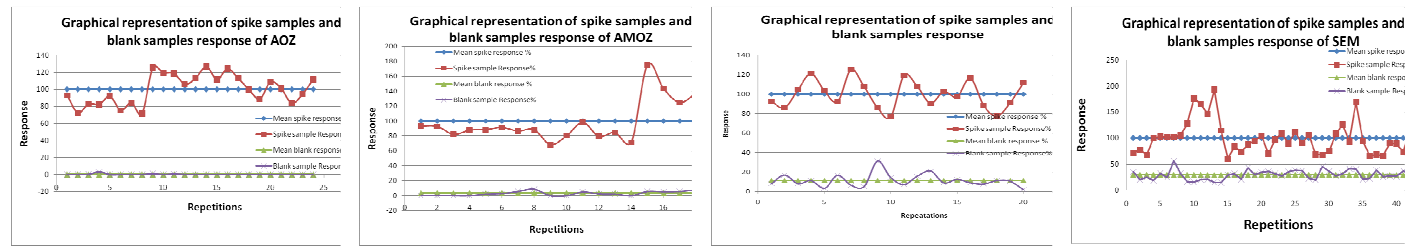

\section{A}
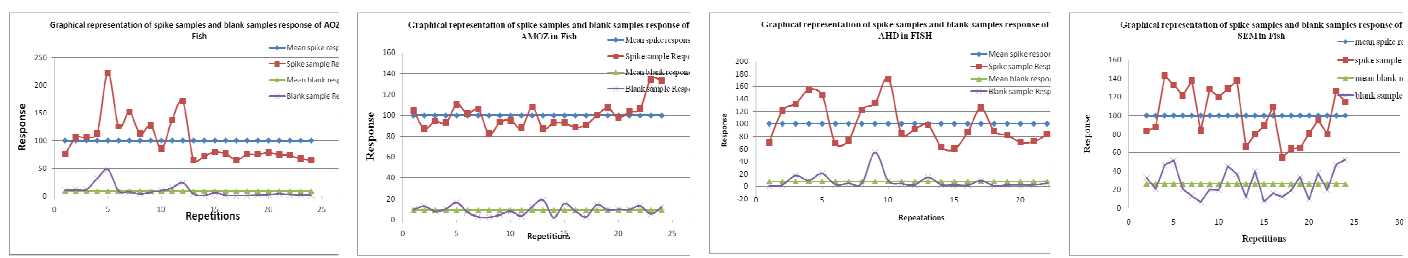

B

Fig.1. Graphical representation of blank samples and spiked samples response of shrimp (A) and fish (B).

Accuracy and precision of the method had also been checked through participation of International Proficiency Testing (PT) having a very satisfactory performance score (Table II). The rate of false positive was below $5 \%$. It indicates that the method is fit for screening analysis of nitrofuran metabolites in fish and shrimp matrix.

Table II. Performance of proficiency tests

\begin{tabular}{|c|c|c|c|c|}
\hline Parameters & $\begin{array}{c}\text { Assigned value } \\
\text { by PT provider } \\
(\mu \mathrm{g} / \mathrm{kg})\end{array}$ & $\begin{array}{c}\text { Value obtained } \\
\text { by the lab } \\
(\mu \mathrm{g} / \mathrm{kg})\end{array}$ & Evaluation & PT provider \\
\hline $\mathrm{AOZ}$ & 0.70 & 0.72 & $\begin{array}{c}\text { Satisfactory } \\
\text { (Equivalent Z score:0.2) }\end{array}$ & \multirow{4}{*}{$\begin{array}{c}\text { Testveritas, Italy, } \\
\text { Veterinary Drug } \\
\text { Residues, round of } \\
\text { September } 2019 . \text { Lab } \\
\text { code } 29 \\
\text { Sampe code: } \\
\text { FI+SH1935-1 } \\
\text { Sampe code: } \\
\text { FI+SH1935-2 }\end{array}$} \\
\hline AMOZ & 1.03 & 0.97 & $\begin{array}{c}\text { Satisfactory } \\
\text { (Equivalent Z score: }-0.25 \text { ) }\end{array}$ & \\
\hline AHD & $<0.5$ & $<0.5$ & Satisfactory & \\
\hline SEM & $<0.75$ & $<0.75$ & Satisfactory & \\
\hline
\end{tabular}

According to the Commission Decision 2002/675/EC, a suspected non-compliant result obtained by a screening method needs to be confirmed by an analytical method able to give structural information of the analyte. For analysis of residue of nitrofuran antibiotics in food, several confirmatory methods based on mass spectrometric detection have been developed by others. Results from analysis of unknown samples by the developed ELISA method were comparable to those obtained by a liquid chromatography-tandem mass spectrometry (LC- 
SIMULTANEOUS AND FAST DETERMINATION OF ANTIBIOTICS AS NITROFURAN METABOLITES

MS/MS) methods. MS based methods can be used for confirmation in the case of suspected samples achieved from the ELISA screening protocols here described. From the study it can be concluded that the proposed method is suitable for qualitative and semi-quantitative screening analysis of nitrofuran metabolites in fish and shrimp muscle in conformity with the current EU performance requirements before exporting to EU and other countries.

\section{Literature Cited}

Alam, M.A., T.M. Waliullah, A.M. Yeasmin, M.S. Islam and M.M. Mia, 2014. A simultaneous method development, validation and confirmatory analysis of AMOZ, AOZ, AHD and SEM in katla fish (Catla catla) and bagda shrimp (Peneaus monodon) by UPLCMS/MS (QPXE). J. Biotechnol. Biosafety, 2(3): 102-112

Barbosa, J., S. Moura, R. Barbosa, F. Ramos and M.I.N. Silveira, 2007. Determination of nitrofurans in animal feeds by liquid chromatography-UV photodiode array detection and liquid chromatography-ionspray tandem mass spectrometry. Anal. Chim. Acta, 586: 359365 .

Commission Decision 2002/657/EC of 12 August 2002 implementing Council Directive 96/23/EC concerning the performance of analytical methods and the interpretation of results. Official J. Eur. Commun., L221: 8-36.

Commission Decision 2003/181/EC of 13 March 2003 amending Decision 2002/657/EC as regards the setting of minimum required performance limits (MRPLs) for certain residues in food of animal origin. Official J. Eur. Commun., L71/17.

Commission Regulation, 1995. Official J. Eur. Commun., L143: 26-30

CRL Guidance Paper of $7^{\text {th }}$ December 2007. CRLs view on state of the art analytical methods for national residue Control plans, 1-8.

CRLs 2010. Guidelines for the validation of screening methods for residues of veterinary medicines (Initial validation and transfer), 1-18.

DoF 2014. National Fish Week 2014 Compendium (in Bangla). Department of Fisheries, Ministry of Fisheries and Livestock, Bangladesh $144 \mathrm{p}$.

DoF 2019. National Fish Week 2019 Compendium (in Bangla). Department of Fisheries, Ministry of Fisheries and Livestock, Bangladesh $160 \mathrm{p}$.

Hossain, M.B., S. Ahmed, M.F. Rahman, B.Y. Kamaruzzaman, K.C.A. Jalal and S.M.N. Amin, 2013. Method development and validation of nitrofuran metabolites in shrimp by Liquid Chromatographic Mass Spectrometric System. J. Biol. Sci., 13(1): 33-37.

ISO 11843. Capability of detection -Part1: terms and definition, Part 2: methodology in the linear calibration curve, 1997.

Scortichini, G., L. Annunziata, M.N. Haouet, F. Benedetti, I. Krusteva and R. Galarini, 2005. ELISA qualitative screening of chloramphenicol in muscle, eggs, honey and milk: method validation according to the Commission Decision 2002/657/EC criteria, Anal. Chim. Acta, 535: $43-48$ 